\title{
Gynaecological consultation in patients with the irritable bowel syndrome
}

\author{
ALISON PRIOR AND P J WHORWELL \\ From the Department of Medicine, University Hospital of South Manchester, Manchester
}

SUMMARY A 12 month follow up study to assess the impact of symptoms suggestive of irritable bowel syndrome in women presenting to gynaecology clinics with pelvic pain is reported. Of 71 women $37(52 \%)$ had symptoms suggestive of irritable bowel syndrome at presentation. A firm gynaecological diagnosis was reached in only three $(8 \%)$ women positive for irritable bowel syndrome compared with $15(44 \%)$ without $(p=0.002)$. After 12 months $24(65 \%)$ women with irritable bowel syndrome were still symptomatic compared with $11(32 \%)$ without $(p=0 \cdot 01)$. This study shows that women with irritable bowel syndrome frequently attend gynaecological clinics but rarely have gynaecological pathology and the prognosis is poor in terms of resolution of their pain.

Irritable bowel syndrome (IBS) is a common condition affecting up to $15 \%$ of the general population. ${ }^{12}$ It may be associated with non-gastrointestinal manifestations such as urinary symptoms and dyspareunia $^{3}$ which can lead to a gynaecological referral in young women. It has also been shown that in women presenting with pain up to $60 \%$ with negative laparoscopies have symptoms suggestive of IBS. ${ }^{4}$ The effect of the presence of IBS on the outcome of a gynaecological consultation, however, has not been assessed.

\section{Methods}

PATIENTS

Eighty consecutive patients (aged 18-68 years) presenting to the gynaecology outpatient department with abdominal pain completed a questionnaire regarding gastroenterological symptoms. This was done independently from, and the results not made available to, the gynaecologist assessing the patient. The criteria for the diagnosis of IBS were all of the followings: abdominal pain more than once per month, abdominal distension at times other than menstruation and a disordered bowel habit (consti-

Address for correspondence: Dr A Prior, University Hospital of South Manchester, Nell Lane, West Didsbury, Manchester M20 8LR.

Accepted for publication 14 November 1988. pation, diarrhoea, or alternating constipation/ diarrhoea). Patients were classified as IBS negative if they had the above symptoms but also gave a history of inflammatory bowel disease or previous gastrointestinal surgery. After a period of 12 months, and without knowledge of their IBS classification, patients were reinterviewed and their case records examined. The outcome of the gynaecological consultation and treatment was classified as good (abdominal pain better or no longer present) or poor (pain unchanged or worse).

\section{Results}

Of the 80 patients $41(51 \%)$ had symptoms suggestive of IBS. Nine patients could not be traced and full follow up information was thus available for 71 women. Of these, $37(52 \%)$ originally had symptoms suggestive of IBS.

From Table 1 it can be seen that IBS was strongly associated with the persistence of symptoms. After 12 months $65 \%$ of women with IBS were still symptomatic compared with $32 \%$ of women without $\left(\chi^{2}(\mathrm{df}=1)=6 \cdot 2 \mathrm{p}=0.01\right)$.

By a combination of clinical examination and investigation involving one or more of ultrasound scanning, examination under anaesthesia and laparoscopy a firm gynaecological diagnosis was reached in only three of the $37(8 \%)$ patients with IBS 
Table 1 Summary of study results

\begin{tabular}{|c|c|c|c|}
\hline & $\begin{array}{l}\text { Patients } \\
\text { with IBS } \\
(\%)\end{array}$ & $\begin{array}{l}\text { Patients } \\
\text { without } \\
\text { IBS }(\%)\end{array}$ & Significance \\
\hline Total & 37 & 34 & \\
\hline Good outcome & $13(35 \%)$ & $23(68 \%)$ & \\
\hline Poor outcome & $24(65 \%)$ & $11(32 \%)$ & $p=0 \cdot 01$ \\
\hline Definite gynaecological diagnosis & $3(8 \%)$ & $15(44 \%)$ & $n=0.000$ \\
\hline No definite diagnosis & $34(92 \%)$ & $19(56 \%)$ & $p=0.002$ \\
\hline
\end{tabular}

compared with 15 of the $34(44 \%)$ patients without $\operatorname{IBS}\left(\chi^{2}(\mathrm{df}=1)=10 \cdot 3 \mathrm{p}=0.002\right)$ (Table 2$)$.

In the 19 patients without IBS in whom no definite gynaecological diagnosis was reached there were seven subjects thought to have endometriosis or pelvic inflammatory disease. This was not confirmed, however, as no further investigations were performed. There were also three women in this group with a bowel disturbance but no bloating who did not therefore meet our criteria for IBS.

A history including enquiry about bowel habit together with either abdominal distension or relationship of pain to defecation was taken by the gynaecologist in $13(18 \%)$ of the total 71 patients. In $29(41 \%)$ no gastrointestinal history appeared to have been taken at all and in the remainder only a limited enquiry regarding gastroenterological symptoms had been made. A diagnosis of IBS was made by the gynaecologist in six women all of whom had been classified as positive by the questionnaire. Appropriate treatment had been recommended in four of these.

Nine of the 71 women underwent laparotomy of which four had IBS. In two of the patients with IBS hysterectomy was performed for pain and gave symptomatic relief in one. In the five women without IBS all had surgery because of pain (three hysterectomy, two oophorectomy) with a good result in three.

\section{Discussion}

The present study confirms that symptoms suggestive of IBS frequently occur in women presenting to gynaecology clinics with abdominal pain. When IBS symptoms were present very few women were found to have gynaecological pathology. This suggests that IBS may be important in the aetiology of pelvic pain in such patients and should be sought after. In the present study a diagnosis of IBS was made by the gynaecologist in only six women largely because an appropriate gastroenterological history was not taken.

The prognosis in terms of resolution of pain was
Table 2 Gynaecological diagnoses in patients with and without IBS

\begin{tabular}{llc}
\hline & IBS & Non-IBS \\
\hline Endometriosis & 2 & 3 \\
Pelvic inflammatory disease & 1 & 6 \\
Ovarian cyst & 0 & 2 \\
Fibroid uterus & 0 & 2 \\
Uterine prolapse & 0 & 1 \\
Severe adhesions & 0 & 1 \\
Total & 3 & 15 \\
\hline
\end{tabular}

found to be much worse in those with IBS than in those without. Sixty five per cent of IBS subjects still had troublesome symptoms at 12 months compared with only $32 \%$ without. This compares less favourably than with the prognosis of IBS patients attending gastroenterological clinics where $32-52 \%$ of subjects do not do well on follow up. ${ }^{-b-8}$ One explanation for this discrepancy may be that patients with IBS referred to gynaecological clinics represent a more severe form of the disorder. Alternatively it is well known that patients with IBS often respond well to reassurance and a sympathetic explanation of their symptoms. ${ }^{9}$ Patients were often discharged from the gynaecological clinics without a diagnostic label and this may have lead to continuing concern about symptoms.

Patients with chronic abdominal pain for which no cause can be found are often subjected to surgery which fails to achieve symptom relief. ${ }^{111}$ In the present study the majority of patients in whom a definitive gynaecological diagnosis could not be made were discharged from follow up and unnecessary surgery was therefore not a common finding. It may be, however, that if symptoms persisted over a period of several years further referrals and surgical intervention might occur.

Three of the 37 women with symptoms suggestive of IBS were found to have definite gynaecological pathology. It may well be that this association was coincidential or alternatively it is possible that there may be symptom overlap between IBS and some gynaecological pathologies. Clearly the numbers involved in this study cannot adequately answer this question but of the three women classified as having IBS and gynaecological pathology only one felt better as a result of specific therapy for the gynaecological problem. This improvement, however, was restricted to abdominal pain but with persistence of abdominal distension and a disturbed bowel habit.

This study adds to an increasing body of evidence that there may be overlap between gastroenterological and gynaecological practice. The management of women with chronic lower abdominal pain may be improved by a joint approach to the problem. 
We thank Professor M Elstein, Drs P J Haynes and P $\mathrm{J}$ Hirsch, and Mr J B Jones for allowing us to study their patients.

\section{References}

1 Thompson WG, Heaton KW. Functional bowel disorders in apparently healthy people. Gastroenterology 1980; 79: 283-8.

2 Drossman DA, Sandler RS, McKee DC, Lovitz AJ. Bowel dysfunction amongst subjects not seeking health care. Gastroenterology 1982; 83: 529-34.

3 Whorwell PJ, McCallum M, Creed FH, Roberts CT. Non-colonic features of irritable bowel syndrome. Gut 1986; 27: 37-40.

4 Hogston P. Irritable bowel syndrome as a cause of chronic pain in women attending a gynaecology clinic.
Br Med J 1987; 294: 934-5.

5 Thompson WG. Gastrointestinal symptoms in the irritable bowel syndrome compared with peptic ulcer and inflammatory bowel disease. Gut 1984: 25: 1089-92.

6 Choudhary NA, Truelove SC. The irritable colon syndrome. $Q$ J Med 1962; 31: 307-22.

7 Waller SL, Misiewicz JJ. Prognosis in the irritable bowel syndrome. Lancet 1969; ii: 753-6.

8 Harvey RF, Mauad EC, Brown AM. Prognosis in the irritable bowel syndrome - a 5 year prospective study. Lancet 1987; i: 963-5.

9 Thompson WG. The irritable bowel. Gut 1984; 25: 30520.

10 Moriarty KJ, Dawson AM. Functional abdominal pain: further evidence that whole gut is affected. $\mathrm{Br}$ Med $\mathrm{J}$ 1982; 284: 1670-2.

11 Kingham JGC, Dawson AM. Origin of right upper quadrant pain. Gut 1985; 26: 783-8. 